\title{
Comparison of Outpatient Harmonic Scalpel Tonsillectomy and Traditional Tonsillectomy in Sleep Disordered Breathing
}

\author{
Waipoj Chanvimalueng
}

\begin{abstract}
In this prospective study of 43 patients, 20 patients were operated by the outpatient harmonic scalpel tonsillectomy. The outpatient harmonic scalpel technique was performed by local injection with $2 \%$ Xylocaine with $1: 80,000$ adrenaline solution around palatine tonsils and using harmonic scalpel for dissecting tissue at superior pole until inferior pole of tonsil. Harmonic scalpel will cut and stop bleeding simultaneously and then, using plain catgut 3-0 ligation at the inferior pole of tonsil stops bleeding from tonsil branch of facial artery. All of the patients were followed up for 1 and 3 weeks postoperatively; 19 of 20 (95\%) patients who were operated by the outpatient harmonic scalpel tonsillectomy felt satisfied and in one case, the patients wound healing delayed for 3 weeks. All patients were discharged on the day of admission with no major complication. Twenty-three patients were operated by the traditional tonsillectomy as an inpatient. Twenty of $23(87 \%)$ patients were satisfied and in three cases, the patients had delayed wound healing for 3 weeks. The results of the study conclude that the outpatient harmonic scalpel tonsillectomy is satisfactory and medical treatment cost also is cheaper than the traditional tonsillectomy for the majority of patients.
\end{abstract}

Keywords: Abnormal breathing during sleep, Sleep disordered breathing, Surgery for removing palatine tonsil, Tonsillectomy.

How to cite this article: Chanvimalueng W. Comparison of Outpatient Harmonic Scalpel Tonsillectomy and Traditional Tonsillectomy in Sleep Disordered Breathing. Int J Otorhinolaryngol Clin 2016;8(1):18-21.

Source of support: The author gratefully acknowledges the financial support provided by Thammasat University Research Fund under the TU Research Scholar, Contract No. TP 2/26/2557

Conflict of interest: None

\section{INTRODUCTION}

The standard tonsillectomy has been traditionally performed as an inpatient procedure in Thailand. However, the outpatient tonsillectomy has been reported and compared. ${ }^{1-7}$ These methods included the outpatient

\footnotetext{
Associate Professor

Department of Otolaryngology, Thammasat University, Rangsit Pathum Thani, Thailand

Corresponding Author: Waipoj Chanvimalueng, Associate Professor, Department of Otolaryngology, Thammasat University Rangsit, Pathum Thani, Thailand, Phone: +6625363910, e-mail: drwaipoj@gmail.com
}

harmonic scalpel technique in this study. The traditional tonsillectomy has been performed as an inpatient under general anesthesia, then dissecting tissue with blunt dissector, and finally stop bleeding by electrical pendant. However, the technique of traditional inpatient tonsillectomy is rather expensive and there is inadequate bed for the patient. Moreover, the patient requires a hospital stay for 2 to 3 days. This study describes the outpatient technique of tonsillectomy by using harmonic scalpel..$^{8-11}$ It is simpler and easier than the traditional tonsillectomy procedure and no necessity for hospitalization.

\section{MATERIALS AND METHODS}

This study was approved by Human Research Ethics Committee of Thammasat University (No. 1: Faculty of Medicine) and the date of approval is July 18, 2013. The study is designed to measure the medical treatment cost and satisfaction of the procedure of tonsillectomy referred to as "outpatient" tonsillectomy. The study was carried out at ENT department, in Thammasat University Hospital and patRangsit Hospital from August 1, 2013 to July 31, 2015. Forty-three patients, with sleep disordered breathing that includes snoring and obstructive sleep apnea without bleeding tendency, were included in this prospective study. The most common cause of sleep disordered breathing is chronic hypertrophic tonsillitis. Two procedures of tonsillectomy were utilized: The traditional tonsillectomy and outpatient tonsillectomy with harmonic scalpel. Twenty-three patients were operated by using the traditional tonsillectomy and the other 20 patients were operated by using the outpatient tonsillectomy, which will be described in detail in the technique section. All patients were explained about the techniques, the advantages, and disadvantages of each procedure, including possible complications. Blood test was performed preoperatively. All patients were treated by the author and received periodical postoperative examination follow-up at 1 and 3 weeks.

\section{TECHNIQUE}

The outpatient harmonic scalpel tonsillectomy technique was performed by local anesthesia with $10 \%$ Xylocaine spray at both palatine tonsils and draped. The palatine 


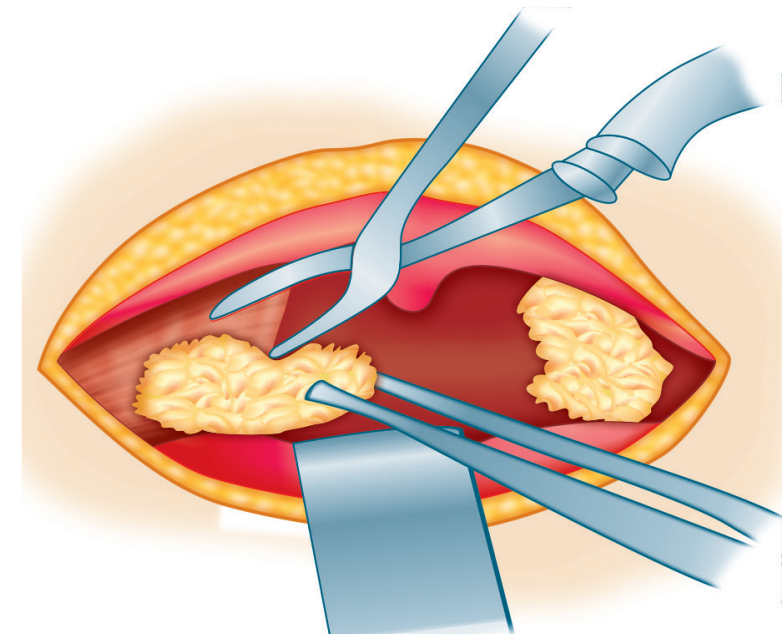

Fig. 1: Harmonic scalpel cut and stop bleeding simultaneously

tonsils were anesthetized with $2 \%$ Xylocaine and with 1:80,000 adrenaline solution around palatine tonsils and using harmonic scalpel for dissecting tissue from superior pole to inferior pole of tonsil (Fig. 1).

Harmonic scalpel will cut and stop bleeding simultaneously and then, plain catgut 3-0 ligation at inferior pole of tonsil was used to stop bleeding from tonsil branch of facial artery and was performed until no bleeding was seen (Fig. 2). Postoperatively, the patient moved from the operation room to short-care unit about 12 hours before discharged to home. All of them were followed up for 1 and 3 weeks.

\section{RESULTS}

Twenty-three patients with the traditional tonsillectomy were compared with 20 patients with the outpatient harmonic scalpel tonsillectomy.

The outcome shows that the average age of the outpatient harmonic scalpel tonsillectomy technique is 38 years old and the traditional tonsillectomy is 35 years old. It is not significant in both groups but the average medical treatment cost of the traditional tonsillectomy is more expensive than the outpatient harmonic scalpel tonsillectomy, the traditional method being priced tripled (Table 1).

Nineteen of $20(95 \%)$ patients who were operated by the outpatient harmonic scalpel tonsillectomy were satisfied and in one case, the patient had delayed wound healing with pain for 3 weeks. All patients were discharged on the day of admission with no major complications, such as bleeding, upper airway obstruction. Twenty-three patients were operated by the traditional tonsillectomy as an inpatient. Twenty of $23(87 \%)$ patients were satisfied and in three cases, the patients delayed wound healing and pain for 3 weeks (Table 2).

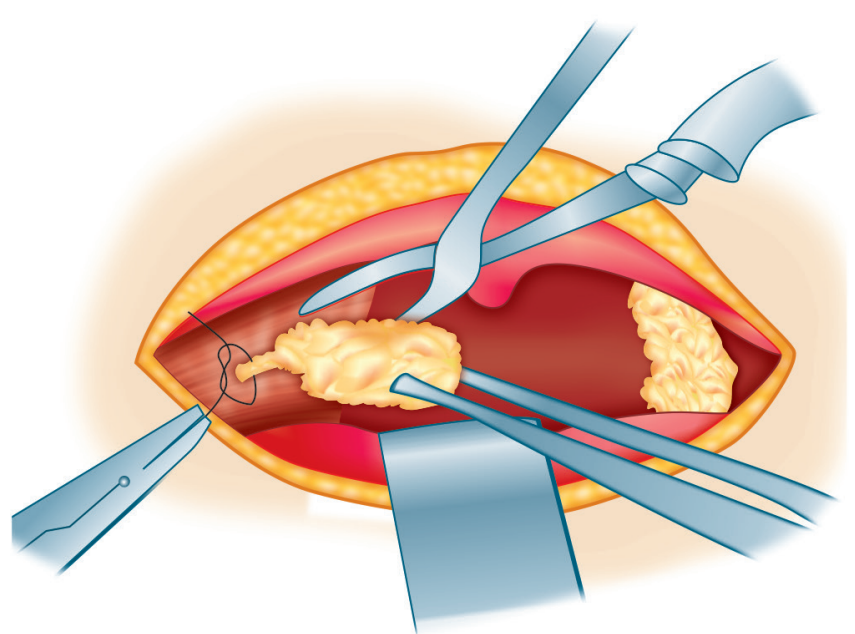

Fig. 2: Plain catgut 3-0 ligate at inferior pole of tonsil

Table 1: Capacity of the patients, type of the operation, age, and medical treatment cost

\begin{tabular}{|c|c|c|c|c|}
\hline $\begin{array}{l}\text { Number of } \\
\text { patients }\end{array}$ & $\begin{array}{l}\text { Medical } \\
\text { treatment cost } \\
\text { of the traditional } \\
\text { tonsillectomy } \\
\text { (Baht) }\end{array}$ & $\begin{array}{l}\text { Age } \\
\text { (yrs) }\end{array}$ & $\begin{array}{l}\text { Medical } \\
\text { treatment cost } \\
\text { of the outpatient } \\
\text { tonsillectomy } \\
\text { (Baht) }\end{array}$ & $\begin{array}{l}\text { Age } \\
\text { (yrs) }\end{array}$ \\
\hline 1 & 18,307 & 37 & 4,475 & 31 \\
\hline 2 & 11,020 & 32 & 5,151 & 39 \\
\hline 3 & 10,705 & 51 & 4,775 & 35 \\
\hline 4 & 13,477 & 24 & 7,130 & 32 \\
\hline 5 & 14,787 & 34 & 4,830 & 25 \\
\hline 6 & 14,922 & 20 & 5,025 & 42 \\
\hline 7 & 16,398 & 18 & 4,115 & 39 \\
\hline 8 & 16,574 & 18 & 6,080 & 37 \\
\hline 9 & 24,539 & 40 & 4,435 & 50 \\
\hline 10 & 19,166 & 50 & 5,650 & 27 \\
\hline 11 & 18,300 & 29 & 6,120 & 33 \\
\hline 12 & 16,212 & 39 & 7,205 & 35 \\
\hline 13 & 17,610 & 36 & 5,105 & 42 \\
\hline 14 & 16,953 & 35 & 4,760 & 44 \\
\hline 15 & 12,155 & 33 & 4,670 & 38 \\
\hline 16 & 18,237 & 43 & 6,320 & 36 \\
\hline 17 & 11,590 & 39 & 5,560 & 51 \\
\hline 18 & 14,285 & 19 & 6,150 & 45 \\
\hline 19 & 17,055 & 47 & 4,550 & 42 \\
\hline 20 & 11,370 & 52 & 5,220 & 40 \\
\hline 21 & 14,773 & 28 & & \\
\hline 22 & 12,423 & 57 & & \\
\hline 23 & 18,125 & 22 & & \\
\hline Mean & 15,608 & 35 & 5,366 & 38 \\
\hline
\end{tabular}

Table 2: Satisfaction, delay in wound healing with pain, and major complication

\begin{tabular}{lll}
\hline & $\begin{array}{l}\text { The traditional } \\
\text { tonsillectomy }\end{array}$ & $\begin{array}{l}\text { The outpatient } \\
\text { tonsillectomy }\end{array}$ \\
\hline $\begin{array}{l}\text { Satisfaction } \\
\begin{array}{l}\text { Delay in wound healing with } \\
\text { pain }\end{array}\end{array}$ & $3(13 \%)$ & $19(95 \%)$ \\
Major complication & 0 & $1(5 \%)$ \\
\hline Total case & 23 & 0 \\
\hline
\end{tabular}




\section{DISCUSSION}

The treatment in sleep disorder breathing patient with chronic hypertrophic tonsillitis is the tonsillectomy ${ }^{12-15}$ and various techniques were used with a certain success ${ }^{16-20}$ but the traditional tonsillectomy will be done as an inpatient with general anesthesia.

The outpatient harmonic scalpel tonsillectomy may provide the solution for inadequate bed for the patient, but the outpatient harmonic scalpel tonsillectomy technique:

- Requires much more skill in using harmonic scalpel for dissecting and stopping bleeding simultaneously

- It is a difficult task for the beginner to dissecting in the appropriate plane.

The above reasons might cause unsatisfied results in the hands of the resident and young colleagues. The success in the outpatient harmonic scalpel tonsillectomy is because it is cheaper than the traditional tonsillectomy, i.e., priced tripled and it is unnecessary for hospitalization. Moreover, no significant difference of satisfaction, delayed wound healing with pain, and no major complication found in the study.

Furthermore, it may be used as an alternative for the full-experienced surgeon whenever he needs a simple procedure for the outpatient surgery. The results of the study conclude that the outpatient tonsillectomy by using harmonic scalpel is as safe and effective as the traditional tonsillectomy for the majority of patients.

\section{CONCLUSION}

A prospective study of tonsillectomy was conducted at Thammasat University Hospital and patRangsit Hospital located at Pathum Thani, Thailand during the period from August 1, 2013 to July 31, 2015. This study was approved by Human Research Ethic Committee of Thammasat University (No. 1: Faculty of Medicine) and 43 patients comprised the study; 23 of them were operated by utilizing traditional tonsillectomy whereas 20 patients were operated by a technique referred to as "outpatient" tonsillectomy. The outpatient harmonic scalpel tonsillectomy dissects and stops bleeding tonsil simultaneously. All 20 patients treated using the outpatient technique discharged on the day of admission with no major complications. The traditional tonsillectomy, on the contrary, requires the patients to stay in the hospital for a few days following the procedure. For 1 and 3 weeks after operation, both groups of patients received postoperative examinations periodically.

The result shows no significance difference in satisfaction and delay in wound healing with pain. For the 20 patients treated with the outpatient harmonic scalpel tonsillectomy, the average medical treatment cost was 5,366 Baht, while for 23 patients treated with the traditional technique, the average medical treatment cost was 15,608 Baht. The price more than tripled. However, no major complications, such as bleeding and upper airway obstruction were reported after follow-up of 1 and 3 weeks. This study would indicate that the outpatient technique saves time and money because the patients require no hospitalization, and is as safe and effective as traditional tonsillectomy.

\section{REFERENCES}

1. Nurliza I, Norzi G, Azlina A, Hashimah I, Sabzah MH. Daycare tonsillectomy: a safe outpatient procedure. Hospital Sultanah Bahiyah, Alor Setar Malaysia experience. Med J Malaysia 2011 Dec;66(5):474-478.

2. Vlastos IM, Athanasopoulos I, Economides J, Parpounas K, Houlakis M. Outpatient cold knife tonsillectomy in toddlers with sleep disordered breathing. B-ENT 2010;6(4): 245-250.

3. Ovesen T, Kamarauskas G, Dahl M, Mainz J. Pain and bleeding are the main determinants of unscheduled contacts after outpatient tonsillectomy. Dan Med J 2012 Feb;59(2): A4382.

4. Laureyns G, Lemkens P, Jorissen M. Tonsillectomy as a daycase surgery: a safe procedure? B-ENT 2006;2(3):109-116.

5. Theilgaard SA, Nielsen HU, Siim C. Risk of hemorrhage after outpatient versus inpatient tonsillectomy. Ugeskr Laeger 2001 Sep;163(37):5022-5025.

6. Granell J, Gete P, Villafruela M, Bolaños C, Vicent JJ. Safety of outpatient tonsillectomy in children: a review of 6 years in a tertiary hospital experience. Otolaryngol Head Neck Surg 2004 Oct;131(4):383-387.

7. Omrani M, Barati B, Omidifar N, Okhovvat AR, Hashemi SA. Coblation versus traditional tonsillectomy: a double blind randomized controlled trial. J Res Med Sci 2012 Jan;17(1):45-50.

8. Sood S, Corbridge R, Powles J, Bates G, Newbegin CJ. Effectiveness of the ultrasonic harmonic scalpel for tonsillectomy. Ear Nose Throat J 2001 Aug;80(8):514-516, 518.

9. Kamal SA, Basu S, Kapoor L, Kulandaivelu G, Talpalikar S, Papasthatis D. Harmonic scalpel tonsillectomy: a prospective study. Eur Arch Otorhinolaryngol 2006 May;263(5):449-454. Epub 2005 Nov 26.

10. Roth JA, Pincock T, Sacks R, Forer M, Boustred N, Johnston W, Bailey M. Harmonic scalpel tonsillectomy versus monopolar diathermy tonsillectomy: a prospective study. Ear Nose Throat J 2008 Jun;87(6):346-349.

11. Kemal O. Harmonic scalpel versus bipolar tonsillectomy: a double-blind clinical trial. Eur Arch Otorhinolaryngol 2012 May;269(5):1533-1536.

12. Karaman M, Tek A, Tuncel A, Oysu C, Sheidaei S. Adult tonsillectomy: relationship between indications and postoperative hemorrhage. Kulak Burun Bogaz Ihtis Derg 2012 Jan-Feb;22(1):21-25.

13. Hoddeson EK, Gourin CG. Adult tonsillectomy: Current indications and outcomes. Otolaryngol Head Neck Surg 2009 Jan;140(1):19-22.

14. Patel HH, Straight CE, Lehman EB, Tanner M, Carr MM. Indications for tonsillectomy: a 10 year retrospective review. Int J Pediatr Otorhinolaryngol 2014 Dec;78(12): 2151-2155. 
15. Liang C, Ruiz AG, Jensen EL, Freidman NR. Indications, clinical course, and postoperative outcomes of urgent adenotonsillectomy in children. JAMA Otolaryngol Head Neck Surg 2015 Mar;141(3):236-244.

16. Singh A, Stephens J, Ghufoor K, Sandhu G. A prospective study comparing PlasmaKnife with bipolar dissection tonsillectomy: a preliminary communication of an emerging technology. Clin Otolaryngol 2008 Jun;33(3):277-280.

17. Sunnergren $\mathrm{O}$, Hemlin C, Ericsson E, Hessén-Söderman AC, Hultcrantz E, Odhagen E, Stalfors J. Radiofrequency tonsillotomy in Sweden 2009-2012. Eur Arch Otorhinolaryngol 2014 Jun;271(6):1823-1827.
18. Aghamohammadi D, Eidi M, Lotfi A, Hosseinzadeh $\mathrm{H}$, Movasaghi R, Motighini N, Bouraima SA. Effect of low level laser application at the end of surgery to reduce pain after tonsillectomy in adults. J Lasers Med Sci 2013 Spring;4(2):79-85.

19. Ragab MA, Atef A, Mosleh M, Metwally B, Fattah AF. Bipolar scissors tonsillectomy: what are the advantages? J Otolaryngol Head Neck Surg 2011 Jun;40(3):256-260.

20. Friedman M, Wilson MN, Friedman J, Joseph NJ, Lin HC, Chang HW. Intracapsular coblation tonsillectomy and adenoidectomy for the treatment of pediatric obstructive sleep apnea/hypopnea syndrome. Otolaryngol Head Neck Surg 2009 Mar;140(3):358-362. 